\title{
Inside Perovskites: Quantum Luminescence from Bulk Cs4PbBr6 Single Crystals
}

Michele De Bastiani, Ibrahim Dursun, Yuhai Zhang, Buthainah A. Alshankiti, XiaoHe Miao, Jun Yin, Emre Yengel, Erkki Alarousu, Bekir Turedi, Jawaher M. Almutlaq, Makhsud I. Saidaminov, Somak Mitra, Issam Gereige, Ahmed Alsaggaf, Yihan Zhu, Yu Han, Iman S Roqan, Jean-Luc Bredas, Omar F. Mohammed, and Osman M. Bakr

Chem. Mater., Just Accepted Manuscript • DOI: 10.1021/acs.chemmater.7b02415 • Publication Date (Web): 01 Aug 2017

Downloaded from http://pubs.acs.org on August 6, 2017

\section{Just Accepted}

"Just Accepted" manuscripts have been peer-reviewed and accepted for publication. They are posted online prior to technical editing, formatting for publication and author proofing. The American Chemical Society provides "Just Accepted" as a free service to the research community to expedite the dissemination of scientific material as soon as possible after acceptance. "Just Accepted" manuscripts appear in full in PDF format accompanied by an HTML abstract. "Just Accepted" manuscripts have been fully peer reviewed, but should not be considered the official version of record. They are accessible to all readers and citable by the Digital Object Identifier (DOI®). "Just Accepted" is an optional service offered to authors. Therefore, the "Just Accepted" Web site may not include all articles that will be published in the journal. After a manuscript is technically edited and formatted, it will be removed from the "Just Accepted" Web site and published as an ASAP article. Note that technical editing may introduce minor changes to the manuscript text and/or graphics which could affect content, and all legal disclaimers and ethical guidelines that apply to the journal pertain. ACS cannot be held responsible for errors or consequences arising from the use of information contained in these "Just Accepted" manuscripts. 
Photovoltaics Engineering Center

SCHOLARONE ${ }^{m}$

Manuscripts

14

15

16

17

19

20

21

23

24

25

27

28

30

31

32

33

34

36

37

39

40

41

42

43
44

45

46

47

48

49

51

52

53

54

55

56

57

59

60 


\title{
Inside Perovskites: Quantum Luminescence from Bulk $\mathrm{Cs}_{4} \mathrm{PbBr}_{6}$ Single Crystals
}

\author{
Michele De Bastiani ${ }^{+-}$II, Ibrahim Dursunt- II, Yuhai Zhangt- II, Buthainah A. Alshankiti ${ }^{\dagger}$, Xiao-He \\ Miao $^{\ddagger}$, Jun Yin ${ }^{\dagger}$, Emre Yengel ${ }^{\dagger}$, Erkki Alarousu ${ }^{\dagger}$, Bekir Turedi ${ }^{\dagger}$, Jawaher M. Almutlaq ${ }^{\dagger}$, Makhsud I. \\ Saidaminov ${ }^{\dagger}$, Somak Mitra ${ }^{\S}$, Issam Gereige ${ }^{\dagger+}$, Ahmed AlSaggaff ${ }^{\dagger+}$, Yihan Zhu ${ }^{\perp}, Y u H_{\text {Han }}^{\perp}$, Iman S. \\ Roqan $^{\S}$, Jean-Luc Bredas ${ }^{\dagger}$, Omar F. Mohammed ${ }^{\dagger *}$ and Osman M. Bakr ${ }^{\dagger *}$
}

†King Abdullah University of Science and Technology (KAUST), KAUST Solar Center (KSC), Division of Physical Science and Engineering (PSE), Thuwal 23955-6900, Kingdom of Saudi Arabia.

‡Imaging and Characterization Core Lab, King Abdullah University of Science and Technology (KAUST), Thuwal 23955-6900, Kingdom of Saudi Arabia.

§Physical Sciences and Engineering Division, King Abdullah University of Science and Technology (KAUST), Thuwal 23955-690o, Kingdom of Saudi Arabia.

††Saudi Aramco Research \& Development Center, Dhahran 31311, Kingdom of Saudi Arabia.

$\perp$ Advanced Membranes and Porous Materials Center, Physical Sciences and Engineering Division, King Abdullah University of Science and Technology (KAUST), Thuwal 23955-690o, Kingdom of Saudi Arabia.

\begin{abstract}
Zero-dimensional perovskite-related structures (oD-PRS) are a new frontier of perovskite-based materials. oDPRS, commonly synthesized in powder form, manifest distinctive optical properties such as strong photoluminescence (PL), narrow emission linewidth, and high exciton binding energy. These properties make oD-PRS compelling for several types of optoelectronic applications, including phosphor screens and electroluminescent devices. However, it would not be possible to rationally design the chemistry and structure of these materials, without revealing the origins of their optical behaviour, which is contradictory to the well-studied $\mathrm{APbX}_{3}$ perovskites. In this work, we synthesize single crystals of $\mathrm{Cs}_{4} \mathrm{PbBr}_{6}$ oD-PRS, and investigated the origins of their unique optical and electronic properties. The crystals exhibit a PL quantum yield higher than $40 \%$, the highest reported for perovskite-based single crystals. Time-resolved and temperature dependent PL studies, supported by DFT calculations, and structural analysis, elucidate an emissive behaviour reminiscent of a quantum confined structure rather than a typical bulk perovskite material.
\end{abstract}

The emergence of metal halide perovskites have upended the conventional wisdom on solution-processed semiconductors, giving rise to low-temperature fabricated photovoltaics and optoelectronics with record photoconversion efficiencies. ${ }^{-7}$ While $\mathrm{ABX}_{3}$-type perovskites have been virtually the sole recipient of research efforts, recent discoveries point towards other, less-known members of the perovskite family. ${ }^{8-15}$ These materials exhibit remarkable optical properties, with a potential to be just as transformative as their more studied $\mathrm{ABX}_{3}$ relatives. In particular, with advancements in materials processing, $\mathrm{Cs}_{4} \mathrm{PbBr}_{6}$ of so-called zero-dimensional perovskite-related semiconductors (oD-PRS) family was obtained, exhibiting appealing optoelectronic properties (strong and narrow photoluminescence) that are distinct from the $\mathrm{ABX}_{3}$ class of perovskite. ${ }^{16-19}$ These new properties place $\mathrm{Cs}_{4} \mathrm{PbBr}_{6}$ in a promising position for applications like color converters for light emitting diodes, electroluminescence devices, lasers, and photodetectors. ${ }^{20-26}$

From the classification point of view, oD-PRS's are a part of the perovskite family of compounds that possess a general formula of $A_{n} B X_{2+n}$. The value of $n$ determines the perovskite's dimensionality in accordance to the connectivity of $\mathrm{BX}_{6}{ }^{4-}$ octahedra: $n=1$ tri-dimensional ${ }_{3} \mathrm{D}$ network of corner-shared octahedra), $n=2$ bi-dimensional (2D, octahedra planes), $n=3$ mono-dimensional ( $1 \mathrm{D}$, octahedra chains), and $n=4$ zero-dimensional (oD, octahedra are not connected or isolated). $\mathrm{Cs}_{4} \mathrm{PbBr}_{6}$ oD-PRS is thus comprised of isolated $\mathrm{PbBr}_{6}{ }^{4-}$ octahedra interspersed with $\mathrm{Cs}^{+}$cations. 9 , 27

However, besides the compelling properties, the origin of the photophysical behavior of $\mathrm{Cs}_{4} \mathrm{PbBr}_{6}$ still remains to be ascertained; particularly, the origin of the photoluminescence (PL). Moreover, the high PL quantum yield 
(PLQY) in solid form represents one of the challenging aspects that contradicts the conventional expectation from typical perovskite materials. Only by unraveling these origins will it be possible to rationally design the chemistry and structure of the oD-PRS, in order to program their color, quantum yield, and exciton association (and dissociation).

We thus synthesized $\mathrm{Cs}_{4} \mathrm{PbBr}_{6}$ single crystals (to probe the materials behavior unencumbered by morphological defects) with the motivation to resolve the current bottleneck in the photophysical behavior and origins hindering the development and exploration of oD-PRS. The $\mathrm{Cs}_{4} \mathrm{PbBr}_{6}$ crystals display a bright green emission centered at $524 \mathrm{~nm}$, an exciton binding energy of $159 \pm 18 \mathrm{meV}$ and a PLQY higher than $40 \%$. Finally, from an in-depth study of timeresolved and temperature dependent PL combined with DFT calculations and structural analysis, we correlate the origin of the PL to the presence of intrinsic defects, such as from bromide vacancies, which endow oD-PRSs their unique quantum behaviour.

$3^{\mathrm{D}}$ metal-halide perovskites recently showed retrograde solubility to readily form single crystals. ${ }^{28-30}$ This technique was also exploited to synthesize $\mathrm{Cs}_{4} \mathrm{PbBr}_{6}$ oD-PRS powder. ${ }^{16-19}$ However, one of the drawbacks of this technique is the formation of $\mathrm{Cs}_{4} \mathrm{PbBr}_{6}-\mathrm{Cs}_{\mathrm{PbBr}}$ mixture phases during the crystallization process. ${ }^{16-19}$ To eliminate the $\mathrm{CsPbBr}_{3}$ phase, which presents poor luminescent properties, several washing steps are required. On the other hand, we found that pure $\mathrm{Cs}_{4} \mathrm{PbBr}_{6}$ single crystals can be easily obtained through the well-established antisolvent vapor-assisted crystallization $^{31-33}$ (AVC) (Figure 1a). To obtain the crystals, $1 \mathrm{ml}$ of precursor solution (o.25M lead bromide $\left(\mathrm{PbBr}_{2}\right)$, and $0.25 \mathrm{M}$ cesium bromide $(\mathrm{CsBr})$ in dimethyl sulfoxide (DMSO)), is placed into the small crystallization flask, inserted in a closed container with $4 \mathrm{ml}$ of diethyl-ether (DE) which plays the role of antisolvent. The low boiling point and high vapor pressure of DE enable its diffusion into the crystallization flask at room temperature, without any additional heating. After 48 hours, an immiscible interface between DE and DMSO is formed in the crystallization flask, resulting in the growth of several small crystals. The crystals are collected and washed with IPA/DMSO (3:1 v:v) mixed solvent (to remove the leftover solution) then dried and stored in a nitrogen atmosphere. The size of the crystals varies according to the crystallization time (i.e. more time spent for crystallization results in larger crystals): here, we collected 50o- $\mu$ m crystals after 48 hours of crystallization. The crystals exhibit a pale green color under ambient light, but when exposed to $365 \mathrm{~nm}$ UV irradiation, they luminesce bright green light (Figure 1b). Scanning Electron Microscopy (SEM) images confirmed the high quality of the crystals with smooth surfaces and well-defined rhomboid shape (Figure 1c).

To investigate the crystalline structure of $\mathrm{Cs}_{4} \mathrm{PbBr}_{6}$ and the quality of the crystals, we performed single crystal $\mathrm{X}$ Ray Diffraction (SC-XRD). SC-XRD data confirmed that $\mathrm{Cs}_{4} \mathrm{PbBr}_{6}$ crystallizes in the trigonal space group $R-3 C$ symmetry (Figure $1 d$ and Supporting Information for details). The unit cell dimensions are $a=b=13.722 \AA$, and $c=17.299 \AA$ (more details can be found in the Supplementary Information, SI). The structure of $\mathrm{Cs}_{4} \mathrm{PbBr}_{6}$ consists of isolated octahedral $\mathrm{PbBr}_{6}{ }^{4-}$ ions interspersed with $\mathrm{Cs}^{+}$cations. To validate the purity of our crystals, we compared the calculated XRD spectrum of the crystals with the experimental powder XRD spectrum of ground oD-PRS powder XRD spectrum (Figure 1e), and confirmed the single and pure phase of the crystals we grew.

To explore the optical properties of the $\mathrm{Cs}_{4} \mathrm{PbBr}_{6}$ single crystals, we collected the absorption and PL spectra (Figure 2a). ${ }^{34,} 35$ The absorption spectrum resembles the spectrum of the oD-PRS powder (Figure $\mathrm{S}$ ), with an extrapolated absorption edge at $538 \mathrm{~nm}(2.30 \mathrm{eV})$.

The PL profile of $\mathrm{Cs}_{4} \mathrm{PbBr}_{6}$ exhibits a standard Gaussian peak centered at $524 \mathrm{~nm}$ with a FWHM of $24 \mathrm{~nm}$. The PL peak partially overlaps with the absorption edge with a small Stokes shift of $\sim 28 \mathrm{meV}$. The PLQY values of $\mathrm{Cs}_{4} \mathrm{PbBr}_{6}$ single crystals were measured with an integrating sphere under an excitation wavelength of $420 \mathrm{~nm}$ (see Figure S2). PLQY values between $40-42 \%$ were obtained from different crystals of differed sizes. To the best of our knowledge, these PLQY values are the highest reported to date for single crystals of halide perovskites. ${ }^{36}$

To further decipher the PL properties of $\mathrm{Cs}_{4} \mathrm{PbBr}_{6}$ single crystals, we performed time-resolved PL experiments using

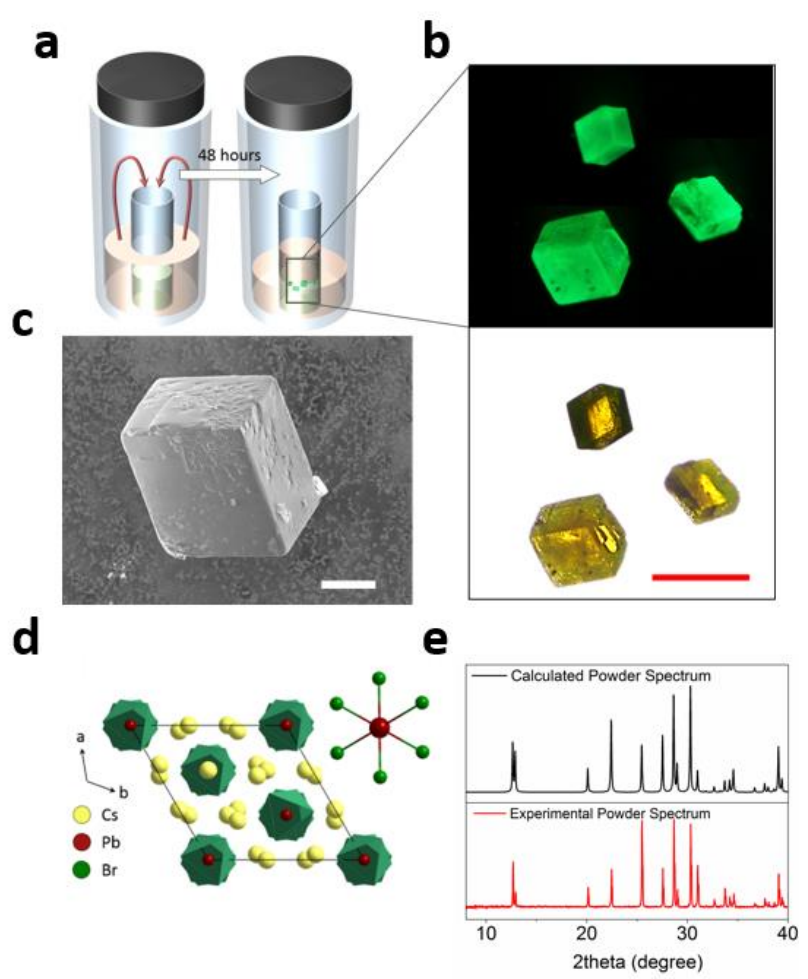

Figure 1. a) Schematic representation of the $\mathrm{Cs}_{4} \mathrm{PbBr}_{6}$ single crystal synthesis by AVC method. b) Fluorescent (top) and optical microscope picture of the single crystals (bottom). Red scale bar: $500 \mu \mathrm{m}$. c) SEM image of the single crystal. White scale bar: $50 \mu \mathrm{m}$. d) Crystal structure of $\mathrm{Cs}_{4} \mathrm{PbBr}_{6}$ obtained from SC-XRD. Green octahedral represent the isolated $\mathrm{PbBr}_{6}$ characteristic of oD-PRS. e) XRD patterns of ground $\mathrm{Cs}_{4} \mathrm{PbBr}_{6}$ (red) and calculated single crystal of $\mathrm{Cs}_{4} \mathrm{PbBr}_{6}$ (black). 
a Streak Camera with picosecond time resolution (Figure $\mathrm{S}_{3}$ ). According to the bi-exponential fitting of our data, we found that the average lifetime for the $\mathrm{Cs}_{4} \mathrm{PbBr}_{6}$ single crystal is $8.18 \mathrm{~ns}$, which is in agreement with previous studies on oD-PRS powders. ${ }^{16,17}$ This PL lifetime is closer to the lifetime of perovskite-quantum dots (QD) than usual perovskite single crystals. 37

To unravel the nature of the optical properties bared by our crystals, we combined density functional theory (DFT) and many-body calculations (Figure $2 \mathrm{~b}$ ). Based on the DFT electronic wavefunctions of the ground state, the optically allowed transitions were calculated by both the random phase approximation (RPA) and the Bethe-Salpeter equation (BSE). The resulting high-energy absorption bands agree well with previous experimental absorption spectra, $3^{8}$ which is due to $\mathrm{Pb}^{2+}(6 \mathrm{~s}) \mathrm{Br}^{-}(4 \mathrm{p}) \rightarrow \mathrm{Pb}^{2+}(6 \mathrm{p})$ interband transitions (see Figure $\mathrm{S}_{4}$ ). As compared to the RPA method, the excitonic band centered at $380 \mathrm{~nm}$ can be well reproduced by the BSE method. Moreover, the deduced band gap for $\mathrm{Cs}_{4} \mathrm{PbBr}_{6}$ appears to be $3.88 \mathrm{eV}$, which greatly differs from our experimental evidence. The apparent mismatch between the theoretical and experimental evidences motivated us to investigate in further depth the origin of the optical properties of $\mathrm{Cs}_{4} \mathrm{PbBr}_{6}$ single crystals.

Thus, to shed light on the mechanism behind the high PLQY, we performed temperature dependent steady-state and time-resolved PL measurements together with structural analysis by combining temperature dependent XRD and Electron Diffraction (ED) analyses (Figure 3). The PL spectra of $\mathrm{Cs}_{4} \mathrm{PbBr}_{6}$ single crystals were collected between $80 \mathrm{~K}$ and $360 \mathrm{~K}$. As shown in Figure 2c, the PL intensity and position of $\mathrm{Cs}_{4} \mathrm{PbBr}_{6}$ single crystals change with temperature. To gain insight into the origin of the PL we investigate the exciton binding energy, by plotting the integrated PL emission intensity with respect to $1 / \mathrm{T}$ (see Figure $4 \mathrm{~b}$ ). The exciton binding energy can be estimated by fitting the experimental data to the following equation: ${ }^{17,39}$

$$
I(T)=\frac{I_{0}}{1+A e^{-E_{b} / k_{b} T}}
$$

where $I_{0}$ is the estimated integrated PL intensity at o K, $E_{b}$ is the exciton binding energy, and $k_{b}$ is the Boltzmann constant. This fitting gives an exciton binding energy of $159 \pm$ $18 \mathrm{meV}$. This value is higher than that in ${ }_{3} \mathrm{D}$ organo-metal halide perovskites, 39 , 40 but comparable to previous findings for oD-PRS powders, ${ }^{16},{ }^{17}$ which suggest a different origin of the PL respect to $3 \mathrm{D}$ bulk perovskites. We also observed a thermal broadening of the PL FWHM, which has been attributed in $3 \mathrm{D}$ perovskites to exciton-phonon coupling, ${ }^{39}$ and a blue shift of the emission with increasing temperature, which has been attributed to the emission from higher-energy states that are populated by electrons through the interaction with phonons. ${ }^{17}, 43-44$

Subsequently, we measured the PL lifetime of the $\mathrm{Cs}_{4} \mathrm{PbBr}_{6}$ single crystals as a function of temperature (Figure $\mathrm{S}_{5}$ ). In hybrid perovskites, the PL lifetime increases with decreasing temperature, due to exciton thermal quenching. ${ }^{4}$ However, $\mathrm{Cs}_{4} \mathrm{PbBr}_{6}$ single crystals show the opposite behavior, i.e. the PL lifetime decreases at lower temperature, a feature independent of excitation power densities (see Figure 4e). Such a behavior was already observed in CdSe colloidal quantum dots. ${ }^{46,} 47$ This trend can be explained by considering the almost negligible electron/phonon interaction at low temperatures, where radiative recombination dominates over non-radiative recombination.

All these phenomena differentiate the optical properties of $\mathrm{Cs}_{4} \mathrm{PbBr}_{6}$ single crystals distinctively from those of the bulk $3 \mathrm{D}$ perovskites family. To clarify the origin of these properties, we thoroughly investigated the structure of $\mathrm{Cs}_{4} \mathrm{PbBr}_{6}$ by means of temperature dependent XRD and Electron Diffraction (ED). In Figure za we report the XRD powder patterns of $\mathrm{Cs}_{4} \mathrm{PbBr}_{6}$ in a range of temperature from $230{ }^{\circ} \mathrm{C}$ to $430{ }^{\circ} \mathrm{C}$. Initially, the XRD peaks are in good agreement with the $\mathrm{Cs}_{4} \mathrm{PbBr}_{6}$ reflections. However, as the temperature rises above $280{ }^{\circ} \mathrm{C}$ secondary reflections corresponding to $\mathrm{CsPbr}_{3}$ start to appear (see inset in Figure 3a). Notably, this thermally-induced $\mathrm{CsPbBr}_{3}$ phase is preserved when the temperature is decreased to ambient conditions, a sign of irreversible conversion. In Figure $3 b$ (top panel) we calculated the sizes of $\mathrm{CsPbr}_{3}$ crystallites from the XRD data (see Supporting Information for the calculations). We observed that the $\mathrm{Cs}_{\mathrm{PbBr}}$ phase appears at $280{ }^{\circ} \mathrm{C}$ with crystals smaller than $10 \mathrm{~nm}$ that subsequently grow when the temperature is further increased. In order to validate the detection limit of our XRD setup, we tested
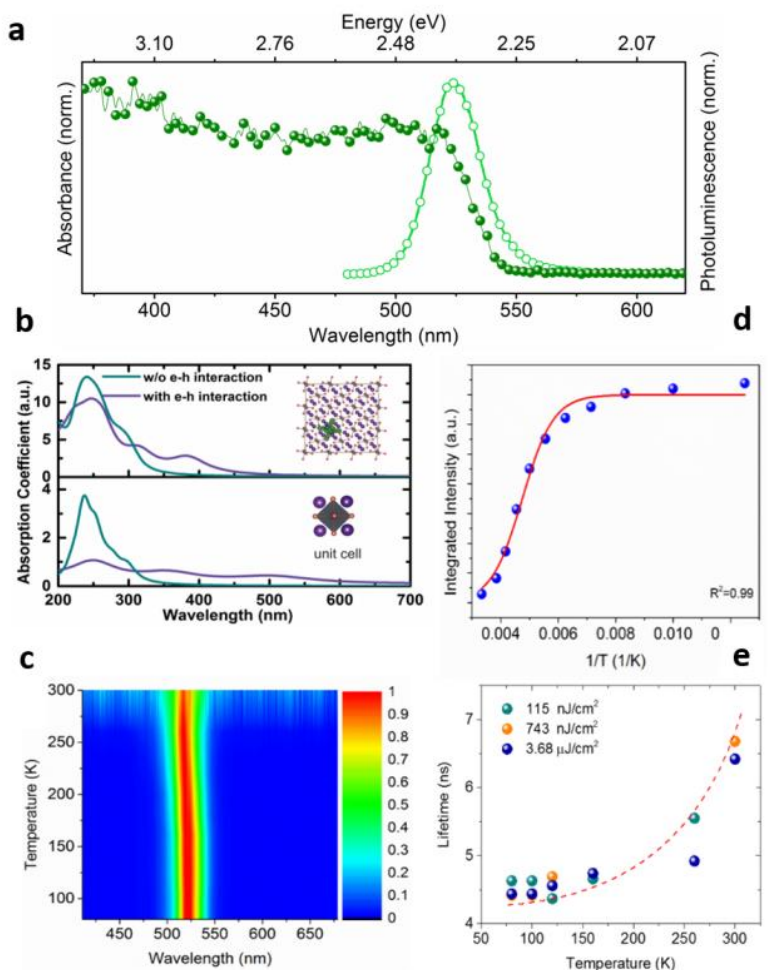

Figure 2. a) Absorption spectrum (full dots) and PL spectrum (hollow dots) of $\mathrm{Cs}_{4} \mathrm{PbBr}_{6}$ single crystal. b) Calculated absorption coefficient of $\mathrm{Cs}_{4} \mathrm{PbBr}_{6}$ single crystal and its single unit without and with electron-hole $(e-h)$ interactions together the exciton wavefunction shown in the inset. c) PL color map as a function of temperature, d) integrate PL intensity, e) average PL lifetime at different temperatures for different excitation fluences, dot line is used as a guide for the eye. 
its sensitivity by detecting $0.5 \mathrm{wt} \%$ of pre-synthesized $\mathrm{CsP}$ $\mathrm{bBr}_{3}$ nanocrystals, which were intentionally mixed with 99.5 wt $\%$ of $\mathrm{Cs}_{4} \mathrm{PbBr}_{6}$ at room temperature (see Figure S6).

Additionally, we investigated the PL spectra of the annealed pristine $\mathrm{Cs}_{4} \mathrm{PbBr}_{6}$ samples (see Figure $3 \mathrm{~b}$ bottom panel). We observed that the PL quickly quenches by raising the temperature as reported in ref ${ }^{17}$. Furthermore, we
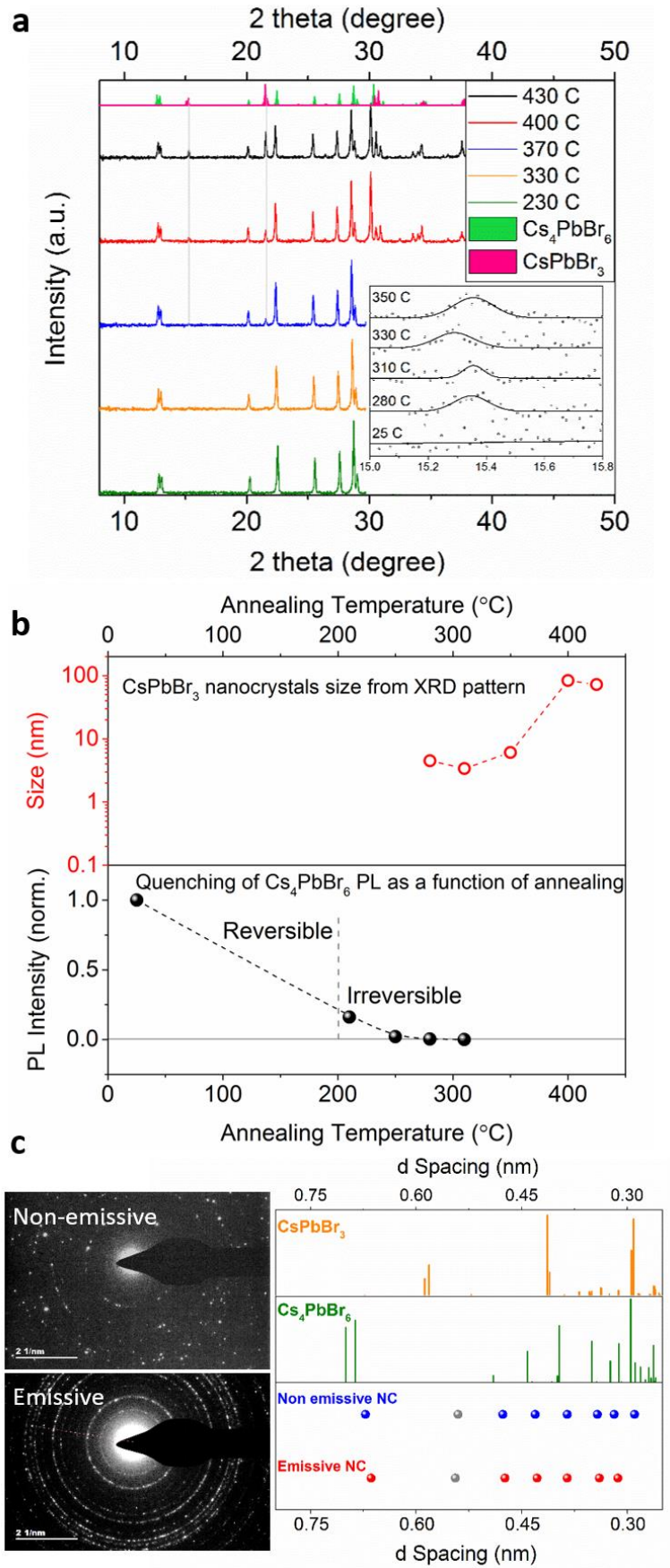

Figure 3. a) $X R D$ powder spectrum of $\mathrm{Cs}_{4} \mathrm{PbBr}_{6}$ during the heating process. In the inset is reported a detailed investigation centered on the peak at 15 degrees. b) $\mathrm{CsPbBr}_{3}$ nanocrystals sizes calculated from the XRD pattern at different temperatures (top panel, red); quenching of the PL as a function of temperature for $\mathrm{Cs}_{4} \mathrm{PbBr}_{6}$ (bottom panel, black). c) ED pattern for non-emissive (blue dots) and emissive (red dots) $\mathrm{Cs}_{4} \mathrm{PbBr}_{6}$ nanocrystals together with the calculated reflection for $\mathrm{Cs}_{4} \mathrm{PbBr}_{6}$ (green) and $\mathrm{CsPbBr}_{3}$ (orange). found that the quenching of the PL was totally reversible until $180{ }^{\circ} \mathrm{C}$. Finally, we noticed that for samples annealed at temperatures higher than $180^{\circ} \mathrm{C}$, the PL quenches irreversibly. Thus, we deduce that: $i$ ) formation of the $\mathrm{CsPBr}_{3}$ phase and quenching of the PL could be connected and ii) the irreversible quenching of the PL, induced by the formation of the nanometric-sized $\mathrm{CsPBBr}_{3}$, phase is contrary to the hypothesis that the PL is originating from nanocrystals impurities..$^{48-50}$ Therefore, to unravel the origin of these phenomena, we took advantages of the latest results on $\mathrm{Cs}_{4} \mathrm{PbBr}_{6}$ nanocrystals. ${ }^{49}$, ${ }^{11} \mathrm{Cs}_{4} \mathrm{PbBr}_{6}$ nanocrystals exhibits totally different optical properties according to their synthesis protocol: according to ref ${ }^{49} \mathrm{Cs}_{4} \mathrm{PbBr}_{6}$ nanocrystals show no emission in the visible spectrum. In contrast, according to ref ${ }^{51}, \mathrm{Cs}_{4} \mathrm{PbBr}_{6}$ nanocrystals show strong green emission with quantum-like behavior. Thus, we synthesized both non-emissive and green-emissive $\mathrm{Cs}_{4} \mathrm{PbBr}_{6}$ nanocrystals and investigated their structural properties by ED (Figure 3C). The ED patterns of emissive and non-emissive nanocrystals both identically match with $\mathrm{Cs}_{4} \mathrm{PbBr}_{6}$, except for an extra spots at $0.54 \mathrm{~nm}$ which can be assigned to a forbidden reflection. No reflections related to $\mathrm{CsPbr}_{3}$ were detected for either sample. The ED results enable us to draw two important conclusions: first, we can exclude the presence of $\mathrm{CsPBr}_{3}$ nanocrystals embedded in the $\mathrm{Cs}_{4} \mathrm{PbBr}_{6}$ matrix, since $\mathrm{CsPbBr}_{3}$ fingerprint reflection are missing from the ED pattern; second, the origin of the quantum emission is not related to any particular crystalline phase due to the identical ED patterns of emissive $\mathrm{Cs}_{4} \mathrm{PbBr}_{6}$ and non-emissive $\mathrm{Cs}_{4} \mathrm{PbBr}_{6}$.

Taken together, all these results point towards a $\mathrm{PL}$ mechanism in $\mathrm{Cs}_{4} \mathrm{PbBr}_{6}$ that is likely independent of the absence or presence of $\mathrm{CsPbBr}_{3}$ nanocrystals.

As we could not find evidence for a role for $\mathrm{CsPBr}_{3}$ inclusions in our emission scenario, we looked for another plausible interpretation of the quantum behavior of bulk $\mathrm{Cs}_{4} \mathrm{PbBr}_{6}$ crystals. Another hypothesis for the origin of the quantum photoluminescence of $\mathrm{Cs}_{4} \mathrm{PbBr}_{6}$ crystals is the presence of shallow and deep energy defects. ${ }^{22}, 53$ These types of defects, in perovskite semiconductors, are widely accepted with the presence of sub-bandgap states whose energies are related to the formation energy of the defect itself.53-55 Among the possible types of defects, halogen vacancies are the most prevalent defects under halogen-poor conditions. ${ }^{54}$ Thus, we posit that bromide vacancies may behave as radiative recombination centers by forming subbandgap states where excitons get trapped. Indeed, the formation of the $\mathrm{CsPbBr}_{3}$ phase at high temperature could be connected to these point defects, which are well known to act as initialization centers for more extended defects such as dislocations. 53 The migration and coalescence of defects, under annealing conditions, leads to the nucleation and clusterization of a $\mathrm{CsPbBr}$ phase, which is accompanied by the irreversible suppression of the PL (Figure 4).

In conclusion, we unraveled the remarkable optical properties of $\mathrm{Cs}_{4} \mathrm{PbBr}_{6}$ oD-PRS single crystals. Our crystals display narrow PL emission centered at $524 \mathrm{~nm}$ and PLQY values higher than $40 \%$. Time-resolved and temperaturedependent PL, combined with DFT calculations, reveal a direct correlation between these properties and those of 
quantum confined structures. Thanks to the structural analysis of emissive and non-emissive oD-PRS we were able to provide new insights on the hotly debated origin of the optical properties of oD-PRS, ruling out any role for $\mathrm{CsPbBr}_{3}$ nanocrystals or inclusion. These findings provide key insights needed to engineer the emissive properties of this rapidly emerging class of materials.

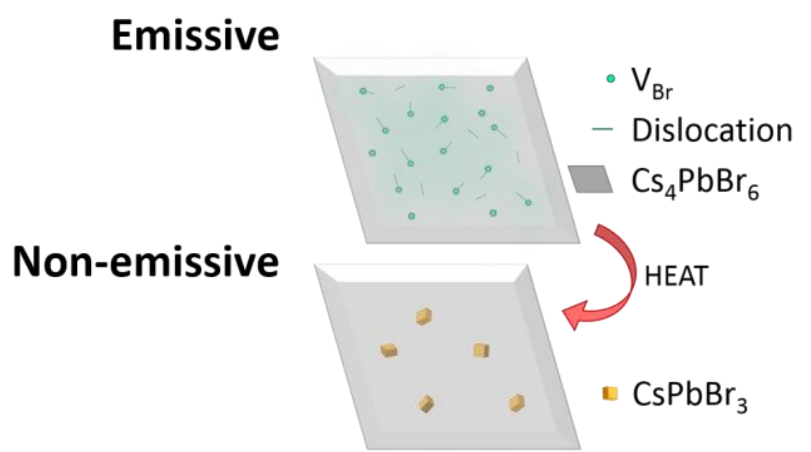

Figure 4. Schematic representation of the possible aggregation mechanism that involves bromide vacancies and $\mathrm{CsPbr}_{3}$ aggregates.

\section{ASSOCIATED CONTENT}

Supporting Information. This material is available free of charge via the Internet at http://pubs.acs.org.

Experimental methods; XRD details; Absorption Spectrum; PL lifetime, and ED.

\section{AUTHOR INFORMATION}

\section{Corresponding Authors}

* Osman M. Bakr. Email: osman.bakr@kaust.edu.sa

* Omar F. Mohammed. Email: omar.ab-

delsaboor@kaust.edu.sa

\section{Author Contributions}

\| These authors contributed equally to this work.

The manuscript was written through contributions of all authors.

\section{ACKNOWLEDGMENT}

The authors acknowledge the financial support of KAUST and Saudi Aramco (Grant RGC/3/3095-01).

\section{REFERENCES}

1 Lee, M. M.; Teuscher J.; Miyasaka T.; Murakami T. N.; Snaith H. J. Efficient hybrid solar cells based on meso-superstructured organometal halide perovskite. Science 2012, 6107, 643-647.

2 Liu, M.; Johnston, M. B.; Snaith, H. J. Efficient planar heterojunction perovskite solar cells by vapour deposition. Nature 2013, 501, 395-398.

3 Docampo, P.; Ball, J. M.; Darwich, M.; Eperon G. E.; Henry J. S. Efficient organometal trihalide perovskite planarheterojunction solar cells on flexible polymer substrates. Nat. Commun. 2013, 4, 2761.

4 Heo, J. H.; Im, S. H.; Noh, J. H.; Mandal, T. N.; Lim, C.; Chang, J. A.; Lee Y. H.; Kim H.; Sarkar A.; Nazeeruddin M. K.; Gratzel M.; Seok I. S. Efficient inorganic-organic hybrid heterojunction solar cells containing perovskite compound and polymeric hole conductors. Nat. Photon. 2013, 7, 486-491.

5 Jeon, N. J.; Noh, J. H.; Kim, Y. C.; Yang, W. S.; Ryu, S.; Seok I. $\mathrm{S}$. Solvent Engineering for high-performance inorganic-organic hybrid perovskite solar cells. Nat. Mater. 2014, 14, 897-903.

6 Im, J.; Jang, I.; Pellet, N.; Gratzel, M.; Park, N. Growth of $\mathrm{CH}_{3} \mathrm{NH}_{3} \mathrm{PbI}_{3}$ cuboids with controlled size for high-efficiency perovskite solar cells. Nat. Nanotechnol., 2014, 9, 927-932.

7 Nie, W.; Tsai, H.; Asadpour, R.; Blancon, J. C.; Neukirch, A. J.; Gupta, G.; Crochet, J. J.; Chhowalla, M.; Tretiak, S.; Alam, M. A.; Wang, H.; Mohite, A. D. High-efficiency solution-processed perovskite solar cells with millimiter-scale grains. Science 2015, 347, 522-525.

8 Smith, M. D.; Pedesseau, L.; Kepenekian; M., Smith, I. C.; Katan, C.; Even, J.; Karunadasa, H. I. Decreasing the electronic confinement in layered perovskites through intercalation. Chem. Sci. 2017, 8, 1960-1968.

9 Tsai, H.; Nie, W.; Blancon, J.C.; Stoumpos, C.C.; Asadpour, R.; Harutyunyan, B.; Neukirch, A.J.; Verduzco, R.; Crochet, J.J.; Tretiak, S.; Pedesseau, L., Even, J.; Mohite, A.D. High-efficiency twodimensional Ruddlesden-Popper perovskite solar cells. Nature 2016, 536, 312-316.

10 Imran, M.; Di Stasio, F.; Dang, Z.; Canale, C.; Khan, A. H.; Shamsi, J.; Brescia, R.; Prato, M.; Manna, L. Colloidal Synthesis of Strongly Fluorescent $\mathrm{CsPbBr}_{3}$ Nanowires with Width Tunable down to the Quantum Confinement Regime. Chem. Mater. 2016, $28,6450-6454$

11 Shamsi, J.; Abdelhady, A. L.; Accornero, S.; Arciniegas, M.; Goldoni, L.; Kandada, A. R. S.; Petrozza, A.; Manna, L. N-Methylformamide as a Source of Methylammonium Ions in the Synthesis of Lead Halide Perovskite Nanocrystals and Bulk Crystals. ACS Energy Lett. 2016, 1, 1042-1048.

12 Akkerman, Q.A.; Motti, S.G.; Srimath Kandada, A.R.; Mosconi, E.; D’Innocenzo, V.; Bertoni, G.; Marras, S.; Kamino, B.A.; Miranda, L.; De Angelis, F.; Petrozza, A.; Prato, M.; Manna, L. 2016. Solution Synthesis Approach to Colloidal Cesium Lead Halide Perovskite Nanoplatelets with Monolayer-Level Thickness Control. J. Am. Chem. Soc. 2016, 138, 1010-1016.

13 Dirin, D. N.; Cherniukh, I.; Yakunin, S.; Shynkarenko, Y.; Kovalenko, M. V. Solution-Grown $\mathrm{CsPbBr}_{3}$ Perovskite Single Crystals for Photon Detection. Chem. Mater. 2016, 28, 8470-8474.

14 Protesescu, L.; Yakunin, S.; Bodnarchuk, M. I.; Bertolotti, F.; Masciocchi, N.; Guagliardi, A.; Kovalenko, M. V. Monodisperse Formamidinium Lead Bromide Nanocrystals with Bright and Stable Green Photoluminescence. J. Am. Chem. Soc. 2016, 138, 1420214205 .

15 Bhaumik, S.; Veldhuis, S.A.; Ng, Y.F.; Li, M.; Muduli, S.K.; Sum, T.C.; Damodaran, B.; Mhaisalkar, S.; Mathews, N. Highly stable, luminescent core-shell type methylammonium-octylammonium lead bromide layered perovskite nanoparticles. Chem. Comm. 2016, 52, 7118-7121.

16 Saidaminov, M. I.; Almutlaq, J.; Sarmah, S.; Dursun, I.; Zhumekenov, A. A.; Begum, R.; Pan, J.; Cho, N.; Mohammed, O. F.; Bakr, O. M., Pure Cs4PbBr6: Highly Luminescent Zero-Dimensional Perovskite Solids. ACS Energy Lett. 2016, 1, 840-845.

17 Chen, D.; Wan, Z.; Chen, X.; Yuan, Y.; Zhong, J., Large-scale room-temperature synthesis and optical properties of perovskiterelated $\mathrm{Cs} 4 \mathrm{PbBr} 6$ fluorophores. J. Mater. Chem. C 2016, 4, 1064610653.

18 Rakita, Y.; Kedem, N.; Gupta, S.; Sadhanala, A.; Kalchenko, V.; Böhm, M. L.; Kulbak, M.; Friend, R. H.; Cahen, D.; Hodes, G., Low-Temperature Solution-Grown $\mathrm{CsPbBr}_{3}$ Single Crystals and Their Characterization. Cryst. Growth Des. 2016, 16, 5717-5725.

19 Saidaminov, I. M.; Mohammed, O. F.; Bakr, O. M. Low-dimensional-networked metal halide perovskites: the next big thing ACS Energy Lett. 2017, 2, 889-896.

20 Pathak, S.; Sakai, N.; Wisnivesky Rocca Rivarola, F.; Stranks, S. D.; Liu, J.; Eperon, G. E.; Ducati, C.; Wojciechowski, K.; 
Griffiths, J. T.; Haghighirad, A. A.; Pellaroque, A.; Friend, R. H.; Snaith, H. J., Perovskite Crystals for Tunable White Light Emission. Chem. Mater. 2015, 27, 8066-8075.

21 Dursun, I.; Shen, C.; Parida, M. R.; Pan, J.; Sarmah, S. P.; Priante, D.; Alyami, N.; Liu, J.; Saidaminov, M. I.; Alias, M. S., Perovskite Nanocrystals as a Color Converter for Visible Light Communication. ACS Photonics 2016, 3, 1150-1156.

22 Kumar, S.; Jagielski, J.; Yakunin, S.; Rice, P.; Chiu, Y.-C.; Wang, M.; Nedelcu, G.; Kim, Y.; Lin, S.; Santos, E. J. G.; Kovalenko, M. V.; Shih, C.-J., Efficient Blue Electroluminescence Using Quantum-Confined Two-Dimensional Perovskites. ACS Nano 2016, 11, 9720-9729

23 Lamberti, F.; Litti, L.; De Bastiani, M.; Sorrentino, R.; Gandini, M.; Meneghetti, M.; Petrozza, A., High-Quality, LigandsFree, Mixed-Halide Perovskite Nanocrystals Inks for Optoelectronic applications. Adv. Energy Mater. 2017, 7, 1601703.

24 Priante, D.; Dursun, I.; Alias, M.S.; Shi, D.; Melniko, V. A.; Ng, T.K.; Mohammed, O.F.; Bakr, O.M.; Ooi, B.S. Recombination mechanisms leading to amplified spontaneous emission at the true-green wavelength in $\mathrm{CH}_{3} \mathrm{NH}_{3} \mathrm{PbBr}_{3}$ perovskites. Appl. Phys. Lett. 2015, 106, 081902.

25 Veldhuis, S.A.; Boix, P.P.; Yantara, N.; Li, M.; Sum, T.C.; Mathews, N.; Mhaisalkar, S.G. Perovskite Materials for LightEmitting Diodes and Lasers. Adv. Mater. 2016, 28, 6804-6834.

26 Yantara, N.; Bhaumik, S.; Yan, F.; Sabba, D.; Dewi, H.A.; Mathews, N.; Boix, P.P.; Demir, H.V.; Mhaisalkar, S. Inorganic Halide Perovskites for Efficient Light-Emitting Diodes. J. Phys. Chem. Lett. 2015, 6, 4360-4364.

27 Saparov, B.; Mitzi, D. B. Organic-Inorganic Perovskites: Structural Versatility for Functional Materials Design. Chem. Rev. 2016, 116, 4558-4596.

28 Maculan, G.; Sheikh, A. D.; Abdelhady, A. L.; Saidaminov, M. I.; Haque, M. A.; Murali, B.; Alarousu, E.; Mohammed, O. F.; $\mathrm{Wu}, \mathrm{T}$.; Bakr, O. M., $\mathrm{CH}_{3} \mathrm{NH}_{3} \mathrm{PbCl}_{3}$ Single Crystals: Inverse Temperature Crystallization and Visible-Blind UV-Photodetector. J. Phys. Chem. Lett. 2015, 6, 3781-3786.

29 Zhumekenov, A. A.; Saidaminov, M. I.; Haque, M. A.; Alarousu, E.; Sarmah, S. P.; Murali, B.; Dursun, I.; Miao, X.-H.; Abdelhady, A. L.; Wu, T.; Mohammed, O. F.; Bakr, O. M., Formamidinium Lead Halide Perovskite Crystals with Unprecedented Long Carrier Dynamics and Diffusion Length. ACS Energy Lett. 2016, 1, 32-37.

3o Saidaminov, M. I.; Abdelhady, A. L.; Murali, B.; Alarousu, E.; Burlakov, V. M.; Peng, W.; Dursun, I.; Wang, L.; He, Y.; Maculan, G.; Goriely, A.; Wu, T.; Mohammed, O. F.; Bakr, O. M., Highquality bulk hybrid perovskite single crystals within minutes by inverse temperature crystallization. Nat. Comm. 2015, 6, 7586.

${ }_{31}$ Peng, W.; Wang, L.; Murali, B.; Ho, K.-T.; Bera, A.; Cho, N.; Kang, C.-F.; Burlakov, V. M.; Pan, J.; Sinatra, L.; Ma, C.; Xu, W.; Shi, D.; Alarousu, E.; Goriely, A.; He, J.-H.; Mohammed, O. F.; Wu, T.; Bakr, O. M., Solution-Grown Monocrystalline Hybrid Perovskite Films for Hole-Transporter-Free Solar Cells. Adv. Mater. 2016, 28, 3383-3390.

32 Peng, W.; Miao, X.; Adinolfi, V.; Alarousu, E.; El Tall, O.; Emwas, A.-H.; Zhao, C.; Walters, G.; Liu, J.; Ouellette, O.; Pan, J.; Murali, B.; Sargent, E. H.; Mohammed, O. F.; Bakr, O. M., Engineering of $\mathrm{CH}_{3} \mathrm{NH}_{3} \mathrm{PbI}_{3}$ Perovskite Crystals by Alloying Large Organic Cations for Enhanced Thermal Stability and Transport Properties. Angew. Chem. Int. Ed. 2016, 55, 10686-1069o. 33 Tidhar, Y.; Edri, E.; Weissman, H.; Zohar, D.; Hodes, G.; Cahen, D.; Rybtchinski, B.; Kirmayer, S., Crystallization of Methyl Ammonium Lead Halide Perovskites: Implications for Photovoltaic Applications. J. Am. Chem. Soc. 2014, 136, 13249-13256.

34 D'Innocenzo, V.; Grancini, G.; Alcocer, M. J. P.; Kandada, A. R. S.; Stranks, S. D.; Lee, M. M.; Lanzani, G.; Snaith, H. J.; Petrozza, A., Excitons versus free charges in organo-lead tri-halide perovskites. Nat. Comm. 2014, 5, 3586.
35 Grancini, G.; Srimath Kandada, A. R.; Frost, J. M.; Barker, A. J.; De Bastiani, M.; Gandini, M.; Marras, S.; Lanzani, G.; Walsh, A.; Petrozza, A., Role of microstructure in the electron-hole interaction of hybrid lead halide perovskites. Nat. Photon. 2015, 9, 695701.

36 Zhang, F.; Zhong, H.; Chen, C.; Wu, X.-g.; Hu, X.; Huang, H.; Han, J.; Zou, B.; Dong, Y., Brightly Luminescent and Color-Tunable Colloidal $\mathrm{CH}_{3} \mathrm{NH}_{3} \mathrm{PbX}_{3}(\mathrm{X}=\mathrm{Br}, \mathrm{I}, \mathrm{Cl}$ ) Quantum Dots: Potential Alternatives for Display Technology. ACS Nano 2015, 9, 45334542.

37 Begun, R.; Parida, M.R; Abdelhady, A.L.; Murali, B.; Alyami, N.; Ahmed, G.H.; Hedhili, M.N.; Bakr, O.M.; Mohammed, O.F. Engineering-Interfacial Charge Transfer in $\mathrm{CsPbBr}_{3}$ Perovskite Nanocrystals by Heterovalent Doping. J. Am. Chem Soc. 2016, 139, 731-737.

38 Kondo, S.; Amaya, K.; Saito, T., Localized optical absorption in $\mathrm{Cs} 4 \mathrm{PbBr} 6$. J. of Phys. Condens. Matter 2002, 14, 2093-2099.

39 Wu, K.; Bera, A.; Ma, C.; Du, Y.; Yang, Y.; Li, L.; Wu, T. Temperature-dependent excitonic photoluminescence of hybrid organometal halide perovskite films. Phys. Chem. Chem. Phys. 2014, 16, 22476-22481.

40 Li, X. M.; Wu, Y.; Zhang, S. L.; Cai, B.; Gu, Y.; Song, J. Z.; Zeng, H. B. CsPbX 3 Quantum Dots for Lighting and Displays: Room-Temperature Synthesis, Photoluminescence Superiorities, Underlying Origins and White Light-Emitting Diodes Adv. Funct. Mater. 2016, 26, 2435-2445.

41 Rudin, S.; Reinecke, T. L.; Segall, B.Temperature-dependent Exciton Linewidths in Semiconductors Phys. Rev. B: Condens. Matter Mater. Phys. 1990, 42, 11218- 11231.

42 Diab, H.; Trippe-Allard, G.; Lédée, F.; Jemli, K.; Vilar, C.; Bouchez, G.; Jacques, V.L.; Tejeda, A.; Even, J.; Lauret, J.S.; Deleporte, E.; Narrow Linewidth Excitonic Emission in Organic-Inorganic Lead Iodide Perovskite Single Crystals. J. Phys. Chem. Lett. 2016, 7, 5093-5100.

43 Wei, K.; Xu, Z.; Chen, R.; Zheng, X.; Cheng, X.; Jiang, T. Temperature-dependent excitonic photoluminescence excited by twophoton absorption in perovskite $\mathrm{CsPbBr} 3$ quantum dots. Opt. Lett. 2016, 41, 3821-3824.

44 Li, J.; Yuan, X.; Jing, P.; Li, J.; Wei, M.; Hua, J.; Zhao, J. Tian, L.; Temperature-dependent photoluminescence of inorganic perovskite nanocrystal films. RSC Adv. 2016, 6, 78311-78316.

45 D'Innocenzo, V.; Srimath Kandada, A. R.; De Bastiani, M.; Gandini, M.; Petrozza, A., Tuning the Light Emission Properties by Band Gap Engineering in Hybrid Lead Halide Perovskite. J. Am. Chem. Soc. 2014, 136, 17730-17733.

46 Gaponenko, M.S.; Lutich, A.A.; Tolstik, N.A.; Onushchenko, A.A.; Malyarevich, A.M.; Petrov, E.P. Yumashev, K.V. Temperature-dependent photoluminescence of $\mathrm{PbS}$ quantum dots in glass: Evidence of exciton state splitting and carrier trapping. Phys. Rev. $B$ 2010, 82, 125320 .

47 De Mello Donegá, C.; Bode, M.; Meijerink, A. Size-and temperature-dependence of exciton lifetimes in CdSe quantum dots. Phys. Rev. B 2006, 74, 085320.

48 Nikl, M.; Mihokova, E.; Nitsch, K.; Somma, F.; Giampaolo, C.; Pazzi, G.P.; Fabeni, P.; Zazubovich, S. Photoluminescence of $\mathrm{Cs}_{4} \mathrm{PbBr}_{6}$ crystals and thin film Chem. Phys. Lett. 1999, 306, 280284 .

49 Akkerman, Q. A.; Park, S.; Radicchi, E.; Nunzi, F; Mosconi, E.; De Angelis, F.; Brescia, R.; Rastogi, P.; Prato, M.; Manna, L. Nearly monodispere insulator $\mathrm{Cs}_{4} \mathrm{PbBr} 6(\mathrm{X}=\mathrm{Cl}, \mathrm{Br}, \mathrm{I})$ nanocrystals, their mixed halide composition, and their transformation into $\mathrm{CsPbX}_{3}$ nanocrystals Nano Lett. 2017, 17, 1924-1930.

50 Quan, L. N.; Bermudez, R. Q.; Voznyy, O.; Walters, G.; Jain, A.; Fan, J. Z.; Zheng, X.; Yang, Z.; Sargent E. H. Highly Emissive Green Perovskite Nanocrystals in a Solid State Crystalline Matrix Adv. Mater. 2017, 29, 1605945. 
51 Zhang, Y.; Saidaminov, I. M.; Dursun, I.; Yang, H.; Murali, B.; Alarousu, E.; Yengel, E.; Alshankiti, B. A.; Bakr, O. M.; Mohammed, O. F. Zero-Dimensional $\mathrm{Cs}_{4} \mathrm{PbBr}_{6}$ Perovskite Nanocrystals $J$. Phys. Chem Lett. 2017, 8, 961-965.

52 Queisser, H. J.; Haller, E. E. Defects in semiconductors: some fatal some vital. Science, 1998, 281, 945-950.

53 Ball, J. M.; Petrozza, A. Defects in perovskite-halides and their effects in solar cells. Nat. Energy 2016, 1, 16149.

54 Kang, J.; Wang L. High defect tolerance in lead halide perovskite $\mathrm{CsPbBr}_{3}$ J. Phys. Chem. Lett. 2017, 8, 489-493.

55 Vanithakumari, S. C.; Nanda K. K. A One-Step Method for the Growth of $\mathrm{Ga}_{2} \mathrm{O}_{3}$-Nanorod-Based White-Light-Emitting Phosphors Adv. Mater. 2009, 21, 3581-3584.
Table of Contents

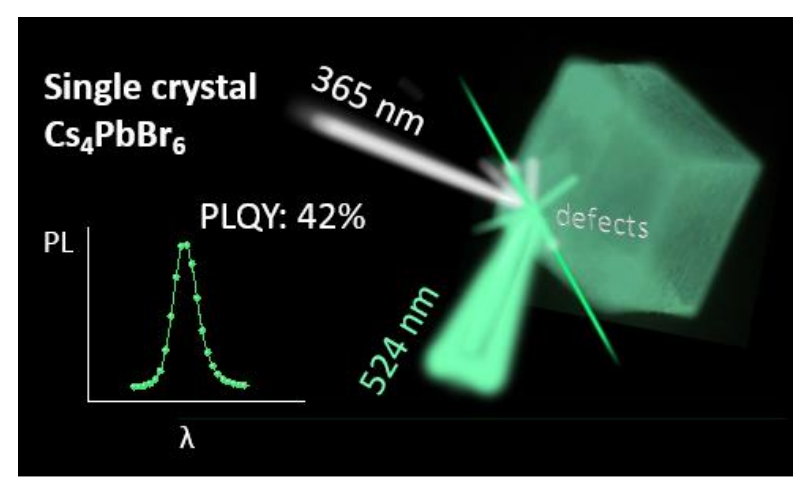

